\title{
Acquired primary hypothyroidism: vaginal bleeding in a quiet child
}

\section{Anne Wormsbecker MD, Cheril Clarson BM BS}

Previously published at www.cmaj.ca

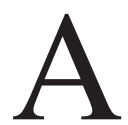
girl aged six years, nine months presented with vaginal bleeding, which included clots about $3 \mathrm{~cm}$ in diameter. The bleeding had started six days previously, and the patient was using three or four menstrual pads a day. The family had initially attributed the bleeding to an unwitnessed straddle injury, but the child denied it. No other signs of puberty were noted, and there was no history of galactorrhea, dry skin, constipation or intolerance to cold. Initial assessment by a pediatric gynecologist confirmed no evidence of trauma, a foreign body or sexual abuse. A complete blood count and the results of coagulation tests were normal.

The parents described the child as having a mild delay in development from infancy, but a formal developmental assessment had not been done. They said she had been quiet and inactive for the past two to three years.

An endocrinologist had assessed the girl for obesity when she was 11 months old. At that time her weight was $15.5 \mathrm{~kg}$ and length $82.2 \mathrm{~cm}$ (both above the 97th percentile). Results of investigations, including the level of serum thyroid-stimulating hormone, were normal, and the obesity was considered exogenous.

Family history revealed a maternal aunt with hypothyroidism and morbid obesity, and the mother had menarche when she was 13 years old.

On examination, the patient was obese and passive. Her height was $118.5 \mathrm{~cm}$, at the 50th percentile (the mid-parental height was between the 90th and 95th percentiles), and she weighed $33.3 \mathrm{~kg}$ (97th percentile) (Figure 1). Her body mass index was $23.9 \mathrm{~kg} / \mathrm{m}^{2}$ (well above the 97th percentile) (Figure 2), heart rate 76 (normal 90-110) beats/min and blood pressure $82 / 53 \mathrm{~mm} \mathrm{Hg}$ (normal for her age). The thyroid gland was not palpable. Breast development on the right was Tanner stage I and on the left stage II $(1 \mathrm{~cm}$ in diameter breast bud). Results of cardiovascular, respiratory and abdominal examination were normal. There was no axillary hair. External genital examination showed no pubic hair, no enlargement of the clitoris and no estrogenization of the vaginal mucosa. Relaxation of the deep tendon reflexes was delayed.

Laboratory investigations confirmed a diagnosis of hypothyroidism. The serum thyroid-stimulating hormone level was markedly elevated, at $>150.0$ (range 0.3-5.0) $\mathrm{mIU} / \mathrm{L}$, and the serum concentration of free thyroxine was depressed, at 2.4 (range 7.0-23.0) pmol/L. Levels of follicle-

\section{Key points}

- Regular documentation of both height and weight is important; a drop in growth rate (crossing percentiles after infancy) or decreased height relative to weight may be a sign of endocrinopathy.

- Precocious menarche is an uncommon presenting feature of hypothyroidism.

- If precocious puberty is associated with short stature or delayed bone age, hypothyroidism should be considered.

stimulating $(5.0 \mathrm{IU} / \mathrm{L})$ and luteinizing $(<0.1 \mathrm{IU} / \mathrm{L})$ hormone were prepubertal, and the serum $17 \beta$-estradiol was 141 (prepubertal range $<96$ ) $\mathrm{pmol} / \mathrm{L}$. The serum prolactin was elevated, at 126 (range 3-29) $\mu \mathrm{g} / \mathrm{L}$. Bone age was five years, nine months $( \pm 17.8$ months $)$ at a chronologic age of six years, nine months. Chromosome analysis showed a $46 \mathrm{XX}$ karyotype.

Thyroid hormone replacement was started at a dose of $12.5 \mu \mathrm{g}$ per day with gradual titration, as is standard practice for severe hypothyroidism. The patient had no further vaginal bleeding, and the family reported a substantial improvement in her sociability and level of activity.

Within six months after initiation of therapy, the serum thyroid-stimulating hormone level was normal; at 30-month follow-up, the level was $0.9 \mathrm{mIU} / \mathrm{L}$, and the serum level of free thyroxine was $19.7 \mathrm{pmol} / \mathrm{L}$ on a dose of L-thyroxine, 112 $\mu \mathrm{g}$ per day.

Despite a marked decrease initially, the body mass index remains elevated $\left(23.6 \mathrm{~kg} / \mathrm{m}^{2}\right.$ at age nine years, three months); however, it is closer to the 97th percentile than it was at the time of diagnosis (Figure 2). The girl's height and weight have become more proportional: the height velocity has accelerated whereas the weight velocity has been relatively stable (Figure 1).

During her time in our care, the patient has become much

From the Dalla Lana School of Public Health, University of Toronto and the Division of Paediatric Medicine, Hospital for Sick Children (Wormsbecker) Toronto, Ont.; and the Department of Pediatrics, University of Western Ontario; and the Section of Pediatric Endocrinology, Children's Hospital, London Health Sciences Centre (Clarson), London, Ont.

CMAJ 2010. DOI:10.1503/cmaj.090883 
more animated. However, despite normal thyroid function and a substantial increase in energy, cognitive development is delayed. No formal cognitive testing had been done before diagnosis, so comparison is not possible. At a chronologic age of seven years, four months, the patient was considered to be functioning at the level of a four- to five-year-old, and most of the delay was in receptive language. Assessment with the Wechsler Intelligence Scale for Children, Fourth Edition, showed her intelligence quotient to be extremely low (first percentile), and the Peabody Picture Vocabulary Test, Third Edition, gave receptive vocabulary scores at the third percentile.

\section{Discussion}

Precocious puberty is generally classified as gonadotropindependent, gonadotropin-independent or a combination of the two. Hypothyroidism is an uncommon gonadotropindependent cause of precocious puberty.

Because this child was clinically and biochemically hypothyroid, the precocious menarche was attributed to acquired primary hypothyroidism, sometimes referred to as Van Wyk-Grumbach syndrome. ${ }^{1}$ In 1960, Van Wyk and Grumbach published a detailed paper describing three patients with galactorrhea, delayed bone age, precocious menarche and hypothyroidism. All three girls had breast development, estrogenized vaginal mucosa and mature endometria shown by ultrasonography, but they had no pubic or axillary hair. All were hypothyroid, and their pubertal changes, which were more advanced than those in our patient, regressed with thyroid hormone replacement therapy. As in our patient, vaginal bleeding also resolved with thyroid hormone replacement therapy. Although not the first to report this condition, Van Wyk and Grumbach proposed a biochemical mechanism for the phenomenon.

Girls with acquired primary hypothyroidism may also present with abdominopelvic masses - large ovarian cysts caused by hyperstimulation. ${ }^{2,3}$ Boys with hypothyroidism may present with macro-orchidism in the absence of virilization. ${ }^{4}$ Poor growth, menarche at early onset of breast development, menarche before onset of pubic or axillary hair, delayed bone age and resolution of pubertal changes after treatment with thyroid hormone replacement are hallmarks of primary hypothyroidism.

There are no reports on the frequency of this condition, ${ }^{5}$ and there is limited information on the long-term prognosis for children with precocious puberty caused by acquired primary hypothyroidism. ${ }^{6}$ One group reported resolution of vaginal bleeding with thyroxine alone and subsequent age-appropriate progression to puberty in 9 of 10 girls with this condition. ${ }^{6}$

\section{Pathophysiology}

Several theories have been proposed to explain precocious puberty caused by hypothyroidism. Van Wyk and Grumbach suggested increased pituitary production of not only thyroidstimulating hormone but also follicle-stimulating and luteinizing hormones and prolactin when there was no negative feedback from thyroid hormone. ${ }^{1}$ The mechanism was dubbed "hormonal overlap in pituitary feedback" and was attributed to molecular similarities between pituitary hormones.

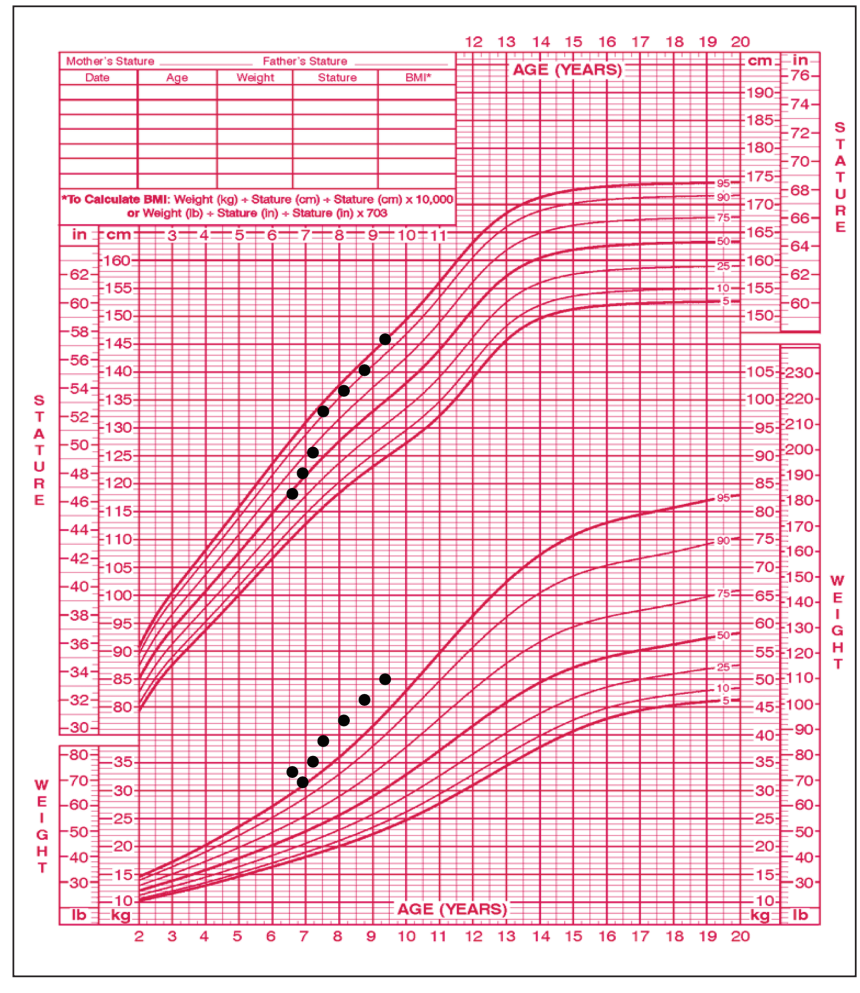

Figure 1: Growth chart for a six-year-old girl showing weight > 97th percentile and height at the 50th percentile at time of diagnosis of hypothyroidism and acceleration in height with thyroid hormone replacement therapy, started at initial visit.

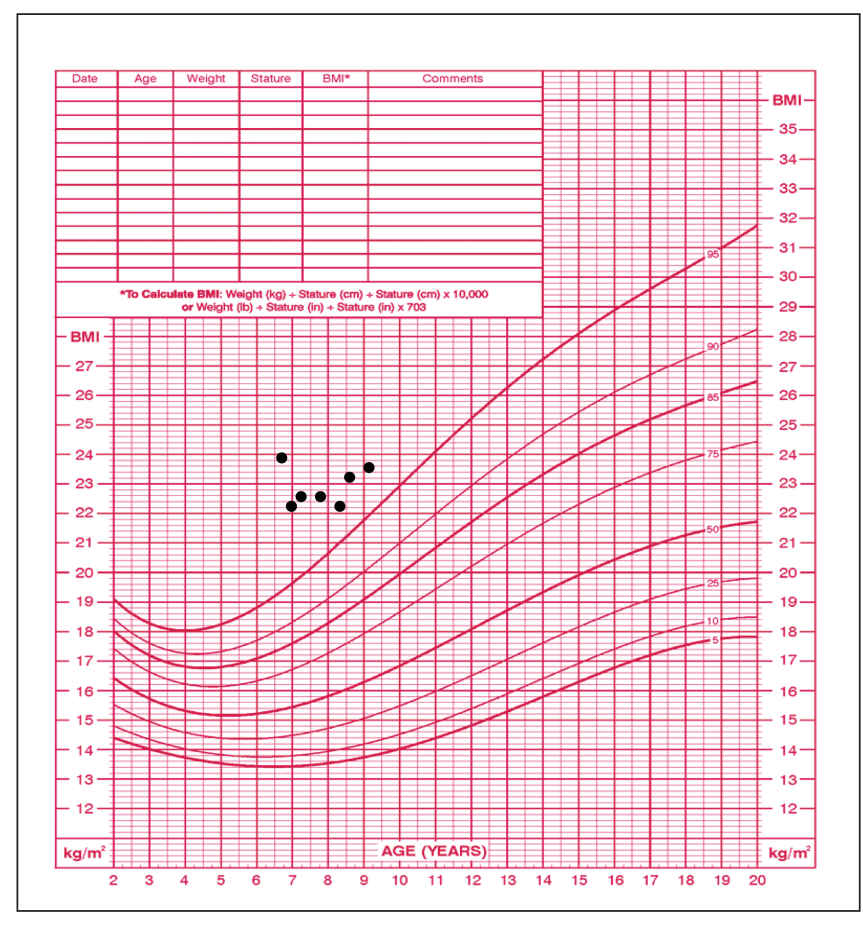

Figure 2: Growth chart for a six-year-old girl showing increased body mass index at time of diagnosis of hypothyroidism and some improvement with thyroid hormone replacement therapy, started at initial visit. 
Another theory is overproduction of prolactin (caused by overlap with the action of thyrotropin-releasing hormone on the pituitary), resulting in either an increased level of gonadotropin-releasing hormone (leading to increased production of follicle-stimulating and luteinizing hormones) or an increased level of estrogen by upregulation of folliclestimulating hormone receptors. ${ }^{7,8}$

The current and most widely accepted theory is that high levels of thyroid-stimulating hormone act on follicle-stimulating hormone receptors because of the molecular similarities between the two hormones. This mechanism, known as "specificity spill over," has been demonstrated in vitro. Athough hypothyroidism is classified as gonadotropin-dependent, the probable binding of thyroid-stimulating hormone to follicle-stimulating hormone receptors removes the gonadotropin from the process. Thyroid-stimulating hormone acts as gonadotropin in the ovaries or testes.

Underlying hypothyroidism should be considered when precocious puberty is associated with deceleration in linear growth, rather than with the typical acceleration in linear growth seen with most other causes of precocious puberty. Unfortunately, growth was not measured in this child from age 18 months until her referral at six years of age.

Athough this is an uncommon presentation of a common disorder, this case highlights the value of regular, accurate monitoring and recording of growth measurements during childhood. Progression to menarche caused by hypothyroidism may be prevented by observing and investigating a significant change in growth parameters. This is a relatively simple process that is essential to facilitate optimal growth during childhood.

This article has been peer reviewed.

Competing interests: None declared.

Contributors: Both authors contributed substantially to the concept, drafting and revising of the article, and both approved the final version submitted for publication.

\section{REFERENCES}

1. Van Wyk JJ, Grumbach MM. Syndrome of precocious menstruation and galactorrhea in juvenile hypothyroidism: an example of hormonal overlap in pituitary feedback. J Pediatr 1960;57:416-35.

2. Indumathi CK, Bantwal G, Patil M. Primary hypothyroidism with precocious puberty and bilateral cystic ovaries. Indian J Pediatr 2007;74:781-3.

3. Campaner AB, Scapinelli A, Machado RO, et al. Primary hypothyroidism presenting as ovarian tumor and precocious puberty in a prepubertal girl. Gynecol Endocrinol 2006;22:395-8.

4. Castro-Magana M, Angulo M, Canas A, et al. Hypothalamic-pituitary gonadal axis in boys with primary hypothyroidism and macroorchidism. J Pediatr 1988;112:397-402.

5. Agwu JC, Karthikeyan A. Precocious puberty. Clin Pediatri (Phila) 2008;47:718 19.

6. Sharma Y, Bajpai A, Mittal S, et al. Ovarian cysts in young girls with hypothyroidism. J Pediatr Endocrinol Metab 2006;19:895-900.

7. Barnes ND, Hayles AB, Ryan RJ. Sexual maturation in juvenile hypothyroidism. Mayo Clin Proc 1973;48:849-56.

8. Costin G, Kershnar AK, Kogut MD, et al. Prolactin activity in juvenile hypothyroidism and precocious puberty. Pediatrics 1972;50:881-9.

9. Anasti JN, Flack R, Froelich L, et al. A potential novel mechanism for precocious puberty in juvenile hypothyroidism. J Clin Endocrinol Metab 1995;80:276-9.

Correspondence to: Dr. Anne Wormsbecker, Hospital for Sick Children, 555 University Ave., 10th floor, Black Wing, Toronto ON

M5G 1X8; anne.wormsbecker@utoronto.ca

The section Cases presents brief case reports that convey clear, practical lessons. Preference is given to common presentations of important rare conditions, and important unusual presentations of common problems. Articles start with a case presentation (500 words maximum), and a discussion of the underlying condition follows (1000 words maximum). Generally, up to five references are permitted and visual elements (e.g., tables of the differential diagnosis, clinical features or diagnostic approach) are encouraged. Written consent from patients for publication of their story is a necessity and should accompany submissions. See information for authors at www.cmaj.ca. 